\title{
Reversal of Venous Blood Flow with Atrial Tachycardia and Hydrops in Fetal Sheep
}

\author{
ALFRED L. GEST, CHRISTOPHER G. MARTIN, ALICIA A. MOÏSE, AND THOMAS N. HANSEN
}

Department of Pediatrics, Baylor College of Medicine, Houston, Texas 77030

\begin{abstract}
The purpose of this project was to characterize the reversal of blood flow in the proximal inferior vena cava (IVC) seen in fetal sheep with pacing-induced atrial tachycardia and hydrops. We successfully operated on seven pregnant ewes at 118-130 d gestation to attach ECG and pacing wires, insert vascular catheters, and place Doppler flow probes around the common aortic trunk and the IVC. We also performed two-dimensional and Doppler ultrasonographic exams at baseline, after initiation of pacing, and daily thereafter. All fetuses developed hydrops. Ultrasonographic appearance of ascites and pleural effusion occurred within $4 \mathrm{~h}$ in four fetuses and within $48 \mathrm{~h}$ in all fetuses. Atrial pacing did not affect arterial $\mathrm{pH}$ or arterial $\mathrm{O}_{2}$ tension, but arterial $\mathrm{CO}_{2}$ tension increased by a small amount. Mean IVC pressure increased $75 \%$, whereas mean aortic pressure remained the same. Concentrations of plasma protein and albumin and the hematocrit did not change with atrial pacing. Doppler ultrasound examination and Doppler IVC flow tracings showed that flow reversal began immediately with atrial pacing and disappeared immediately with cessation of pacing. Reversed flow was $21 \%$ of forward flow. Inspection of simultaneous recordings of ECG, Doppler aortic and IVC flows, and aortic and IVC pressure tracings revealed that the reversed blood flow occurred in diastole in conjunction with atrial contraction and, therefore, could not be due to tricuspid insufficiency. Our findings of increased venous pressure and reversed venous blood flow suggest that ventricular function is impaired and further suggest that oxygen supply to the ventricles may not be sufficient for the increased demand. (Pediatr Res 28: 223-226, 1990)
\end{abstract}

Abbreviations

IVC, inferior vena cava

Pulsatile reversal of blood flow in the IVC occurs in some fetuses with nonimmune hydrops (1). Recently, Nimrod et al. (2) also noted pulsatile reversal of flow in the IVC of fetal lambs that developed hydrops secondary to atrial pacing. We and others have assumed that flow reversal in the IVC of the fetus is most likely the result of tricuspid insufficiency and as such, is a sign of severe myocardial dysfunction from ischemia. If this is the case, then detection of flow reversal in the IVC by external Doppler ultrasound examination might be an indication for immediate intervention in the fetus with nonimmune hydrops.

Received November 28, 1989; accepted May 1, 1990

Correspondence and reprint requests: Alfred L. Gest, M.D., Department of Pediatrics, Baylor College of Medicine, One Baylor Plaza, Houston, TX 77030.

Supported by grants from the American Heart Association, Texas Affiliate American Heart Association, National Center.
The purpose of this project was to characterize the phenomena of flow reversal in the IVC of the fetus with pacing-induced tachycardia and hydrops. We planned to determine the frequency with which flow reversal occurs, time its onset, and determine whether or not it represents tricuspid insufficiency. Assessment of the later point required precise determination of the timing of flow reversal within the cardiac cycle.

\section{MATERIALS AND METHODS}

Surgery. We successfully operated on seven pregnant western range ewes at 118-130 d gestation. We anesthetized the ewes using $30 \mathrm{mg}$ tetracaine hydrochloride supplemented with intermittent i.v. injections of ketamine hydrochloride for sedation, performed a midline cesarean incision to obtain uterine access, and then palpated a rear fetal extremity and withdrew it through a small uterine incision. After infiltrating the lateral popliteal area with $1 \%$ xylocaine, we isolated the artery and vein by blunt dissection, inserted polyvinyl catheters, and advanced them so that their tips lay in the abdominal aorta and in the IVC. Then we returned the extremity to the uterus and closed the uterine incision with a purse string suture.

At this point in the operation, we administered ketamine hydrochloride directly to the fetus for additional anesthesia and performed a thoracotomy in the 2 nd right interspace to gain access to the brachiocephalic artery. For this procedure, we withdrew the fetal head and right fore limb to expose the right

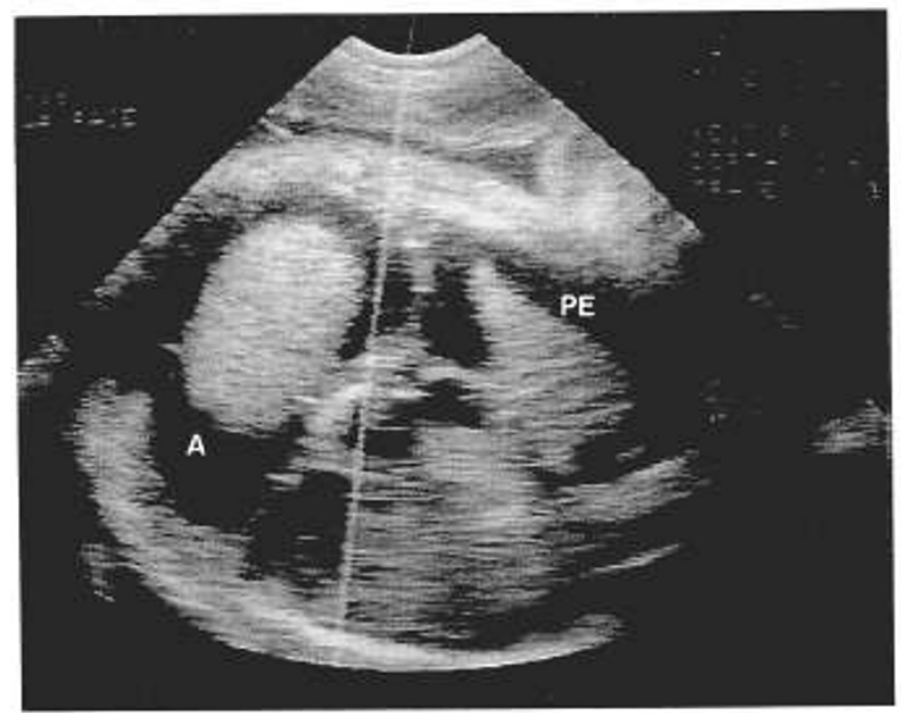

Fig. 1. Two-dimensional ultrasound examination demonstrates ascites $(A)$ and pleural effusions $(P E)$ in a fetal sheep after $12 \mathrm{~h}$ of atrial pacing at 320 beats per min. Four fetuses had ultrasound evidence of ascites after $4 \mathrm{~h}$ of pacing; all had ascites by $48 \mathrm{~h}$. 
Table 1. Effect of atrial pacing on arterial blood gas tensions, hematocrit, and concentrations of protein and albumin*

\begin{tabular}{|c|c|c|c|c|c|c|}
\hline & \multicolumn{3}{|c|}{$\begin{array}{l}\text { Arterial blood } \\
\text { gases }(\mathrm{kPa})\end{array}$} & \multirow[b]{2}{*}{ Hematocrit } & \multirow{2}{*}{$\begin{array}{l}\text { Total protein } \\
(\mathrm{g} / \mathrm{L})\end{array}$} & \multirow{2}{*}{$\begin{array}{c}\text { Albumin } \\
(\mathrm{g} / \mathrm{L})\end{array}$} \\
\hline & $\mathrm{pH}$ & $\mathrm{PaO}_{2}$ & $\mathrm{PaCO}_{2}$ & & & \\
\hline Baseline & $7.37 \pm 0.01$ & $3.07 \pm 0.13$ & $7.07 \pm 0.27$ & $0.29 \pm 0.01$ & $36 \pm 1$ & $20 \pm 1$ \\
\hline Last day & $7.34 \pm 0.02$ & $3.07 \pm 0.27$ & $7.47 \pm 0.27 \dagger$ & $0.30 \pm 0.01$ & $35 \pm 2$ & $20 \pm 1$ \\
\hline
\end{tabular}

* Mean \pm SEM. Metric units: baseline, $\mathrm{PaO}_{2}$ (arterial $\mathrm{O}_{2}$ tension) $23 \pm 1$ torr; $\mathrm{PaCO}_{2}$ (arterial $\mathrm{CO}_{2}$ tension) $53 \pm 2$ torr; total protein $3.6 \pm 0.1 \mathrm{~g} /$ $\mathrm{dL}$; albumin $2.0 \pm 1 \mathrm{~g} / \mathrm{dL}$. Last day, $\mathrm{PaO}_{2} 23 \pm 2$ torr; $\mathrm{PaCO}_{2} 56 \pm 2$ torr $\neq$; total protein $3.5 \pm 0.2 \mathrm{~g} / \mathrm{dL}$; albumin $2.0 \pm 0.1 \mathrm{~g} / \mathrm{dL}$.

$\dagger$ Different from baseline, $p<0.05$.

hemithorax and then placed an appropriately sized circumferential Doppler flow probe around the brachiocephalic artery (3). In addition, we inserted atrial pacing electrodes through an incision in the pericardium over the right atrium, secured them by suturing the edges of the pericardial incision, and then closed the incision between the ribs. Then, through the same skin incision, we bluntly dissected down to the 6th interspace and performed a 2nd thoracotomy to expose the IVC and place another appropriately sized circumferential Doppler flow probe around it near its junction with the right atrium. In addition, we placed ECG electrodes directly on the ventricle through another pericardial incision, and secured them by closing the pericardium. Then we closed this interspace and the initial skin incision, attached an amniotic fluid catheter to the fetal chest for referencing vascular pressures, and returned the fetus to the uterus. Finally, we closed the uterine incision and the ewe's abdominal incision. We gave the ewes meperidine postoperatively for analgesia and antibiotics daily as prophylaxis against infection. All animals recovered for at least $5 \mathrm{~d}$ after surgery before we performed any experiments.

Experimental protocol. During a 4-h baseline period, we measured arterial blood gas tensions, arterial $\mathrm{pH}$, and vascular pressures in addition to total protein and albumin concentrations. We also recorded simultaneous fast speed ECG $(200 \mathrm{~mm} / \mathrm{s})$, phasic brachiocephalic arterial Doppler flow velocity waveforms, and phasic IVC Doppler flow velocity waveforms. Then we paced the right atrium at 320 beats per min and repeated the same measurements daily for the duration of the experiment. Pacing continued around the clock except for brief interruptions, less than 10 min each, occurring when we transported the ewe from the laboratory to the vivarium or when we turned the pacemaker off to observe the effect of discontinuation of pacing on flow reversal.

Our study ended when the ewe began labor (four animals), when the fetus suddenly died (two animals), or when we could no longer effectively pace the atrium (one animal).

Ultrasound examination. We examined the thoracic and abdominal organs with a duplex, mechanical sector scanner, and a 5-MHz medium focus transducer (Mark 600 Ultrasound System, Advanced Technologies Laboratories, Bellevue, WA) and recorded the two-dimensional images on video tape. In addition, we recorded the flow velocity waveform from the proximal IVC, the audio Doppler signal, and the ECG on video tape with a range gated $5-\mathrm{MHz}$ pulsed Doppler transducer. We performed the ultrasound examinations during the baseline period, after pacing for $2 \mathrm{~h}$, and then daily thereafter for the remainder of the study.

Analytical methods. We measured arterial blood gas tensions and $\mathrm{pH}$ using a Radiometer (Tampa, FL) blood gas machine with the sample temperature set at $40^{\circ} \mathrm{C}$ and vascular pressures using p-23 pressure transducers (Statham) and a chart recorder (Gould Inc., Cleveland, OH). Amniotic fluid pressure served as zero reference for vascular pressures. We measured total protein concentration using the Biuret method and determined albumin concentrations by agarose gel electrophoresis.

We digitized the flow velocity waveform obtained from the circumferential flow probe placed around the IVC using a digital graphics tablet and a microcomputer (Digisonics, Inc., Houston, TX) and determined the area under the forward and reverse flow curves of photoenlargements of the chart recording. We averaged measurements from 10 consecutive cardiac cycles and expressed reverse flow as a percent of forward flow (reverse flow/forward flow $\times 100 \%$ ).

Statistical methods. We expressed all data as mean \pm SEM

Table 2. Effect of atrial pacing on vascular pressures and \% reversal of venous blood flow*

\begin{tabular}{cccc}
\hline & \multicolumn{2}{c}{ Vascular pressures $(\mathrm{kPa})$} & Flow reversal \\
\cline { 2 - 3 } & IVC & Aortic & $(\%)$ \\
\hline Baseline & $0.53 \pm 0.13$ & $5.73 \pm 0.27$ & 0 \\
Last day & $0.93 \pm 0.13 \dagger$ & $5.73 \pm 0.27$ & $21 \pm 5 \dagger$ \\
\hline
\end{tabular}

* Mean \pm SEM. Metric units: baseline, $\mathrm{P}_{\mathrm{IVC}}$ (IVC pressure) $4 \pm 1$ torr; $\mathrm{P}_{\mathrm{a} o}$ (aortic pressure) $43 \pm 2$ torr. Last day, $\mathrm{P}_{\mathrm{IVC}} 7 \pm 1$ torr†; $\mathrm{P}_{\mathrm{ao}} 43 \pm 2$ torr.

$\dagger$ Different from baseline, $p<0.05$.

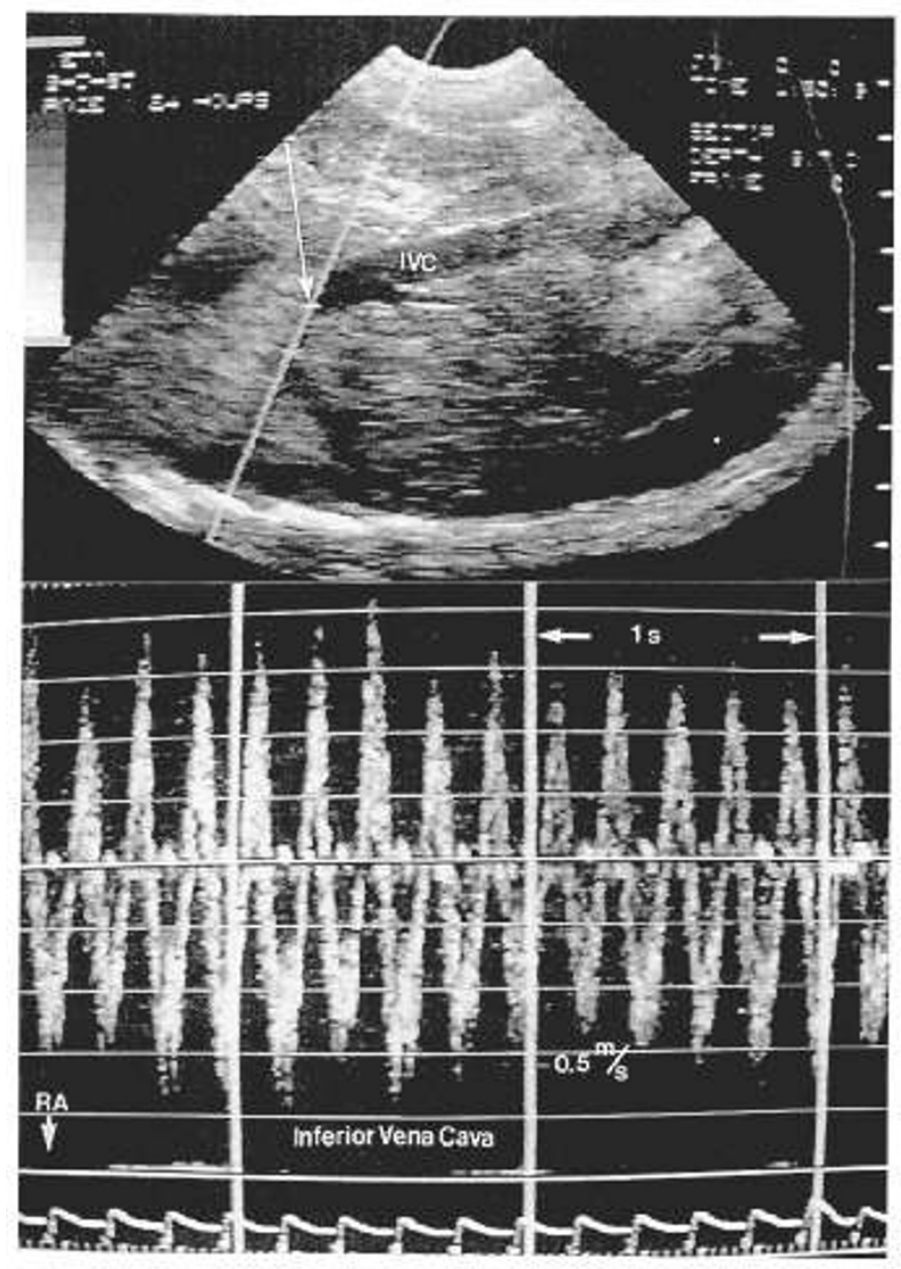

Fig. 2. Doppler ultrasonographic evidence of reversed venous blood flow in the proximal IVC. With atrial pacing, flow in the proximal IVC immediately becomes pulsatile. Flow above the baseline is toward the transducer but away from the right atrium. The flow below the baseline is toward the right atrium. 
and used the paired $t$ test to determine if the values obtained on the last day of the study were statistically different from the baseline. We considered values to be significant if $p$ values were $<0.05$.

\section{RESULTS}

We studied seven fetal sheep $(123 \pm 6 \mathrm{~d}$ gestation $)$ that underwent atrial pacing as described in the experimental protocol for $83 \pm 15 \mathrm{~h}$. We paced all fetuses at 320 beats per min with $1: 1$ atrioventricular conduction. Baseline fetal heart rate was 184 \pm 19 beats per min (SD). At autopsy, the fetal sheep weighed $3.13 \pm 0.14 \mathrm{~kg}$. As in our previous studies, all paced fetuses developed hydrops fetalis. Fetal two-dimensional ultrasound examinations demonstrated the presence of ascites as early as $4 \mathrm{~h}$ after the onset of pacing in four fetuses; after $48 \mathrm{~h}$ of pacing, ascites was present in every fetus (Fig. 1).

Atrial pacing did not affect fetal $\mathrm{pH}$ and arterial $\mathrm{O}_{2}$ tension, but the arterial $\mathrm{CO}_{2}$ tension increased by a small but significant amount (Table 1). Total protein concentration, albumin concentration, and hematocrit remained the same throughout the study. Mean venous pressure increased by $0.40 \mathrm{kPa}$ ( 3 torr) with continuous atrial pacing, and aortic pressure remained unchanged (Table 2).

Doppler echocardiograms performed with the two-dimensional ultrasound studies showed the appearance of pulsatile, reversed venous blood flow in the proximal IVC coincident with the onset of pacing (Fig. 2). This pulsatile flow disappeared with the cessation of atrial pacing. On average, the proportion of reversed to forward flow was $21 \%$ (Table 2 ).

By inspecting simultaneously the fast trace ECG, the aortic Doppler flow tracing, and the vena caval Doppler flow tracing, we found that flow reversal in the IVC occurred during diastole in conjunction with a $\mathrm{P}$ wave and atrial contraction (Fig. 3). There was no reversal of flow during ventricular systole.

\section{DISCUSSION}

We found that flow reversal was a universal accompaniment of nonimmune hydrops secondary to rapid atrial pacing. Flow

\section{Before Pacing}

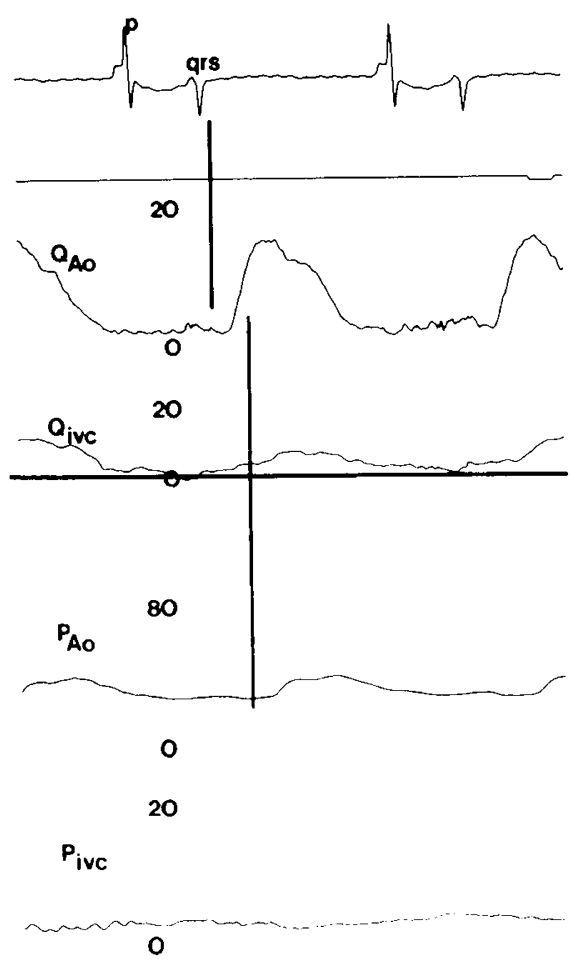

reversal appeared almost immediately with the onset of pacing and ceased with the discontinuation of pacing. The reversed flow represented a substantial proportion of total venous return and, as such, might significantly impair fetal cardiac output. Flow reversal clearly did not represent tricuspid insufficiency because it occurred during diastole, not during ventricular systole. The lack of any evidence for fetal hypoxia or acidosis by arterial blood gas tensions at the time of onset of flow reversal or of nonimmune hydrops indicates that flow reversal is not a good marker for fetal asphyxia.

The presence of flow reversal in conjunction with atrial systole suggests alteration of the pressure-volume relationships of the right ventricle so as to impede ventricular filling. In our fetuses, mean systemic venous pressure nearly doubled as hydrops developed. Central venous pressure is a balance between the amount of blood returning to the heart and the ability of the heart to pump the blood back to the body. In the absence of peripheral vasodilatation or arterial venous fistulae, the pumping ability of the heart determines the venous pressure. At rates up to 300 beats per min, atrial pacing increases ventricular contractility in the lamb and decreases left ventricular end diastolic pressure (4). Interestingly, at rates above 310 beats per min, atrial pacing reduces ventricular output in fetal lambs (5). These results, in conjunction with our finding of universally increased venous pressure at pacing rates above 300 beats per min, suggest that at very high pacing rates there is some element of ventricular dysfunction. One possible explanation for this ventricular dysfunction could be that oxygen supply to the ventricle is not adequate for the increased demands of pacing. In adults in whom oxygen supply to the ventricle is limited by ischemic heart disease, rapid atrial pacing uniformly impairs ventricular relaxation and increases left ventricular end diastolic pressure $(6,7)$. Other investigators have shown that with atrial pacing, increased oxygen delivery to the ventricle by increased coronary blood flow may not be adequate to meet the demands imposed by the increased heart rate, especially at pacing rates exceeding 1.5 times the basal heart rate $(8,9)$. In our experiments, the rate of pacing was roughly 1.75 the basal heart rate, so it is possible that the demand for oxygen exceeded the supply and that this accounted

\section{During Pacing}

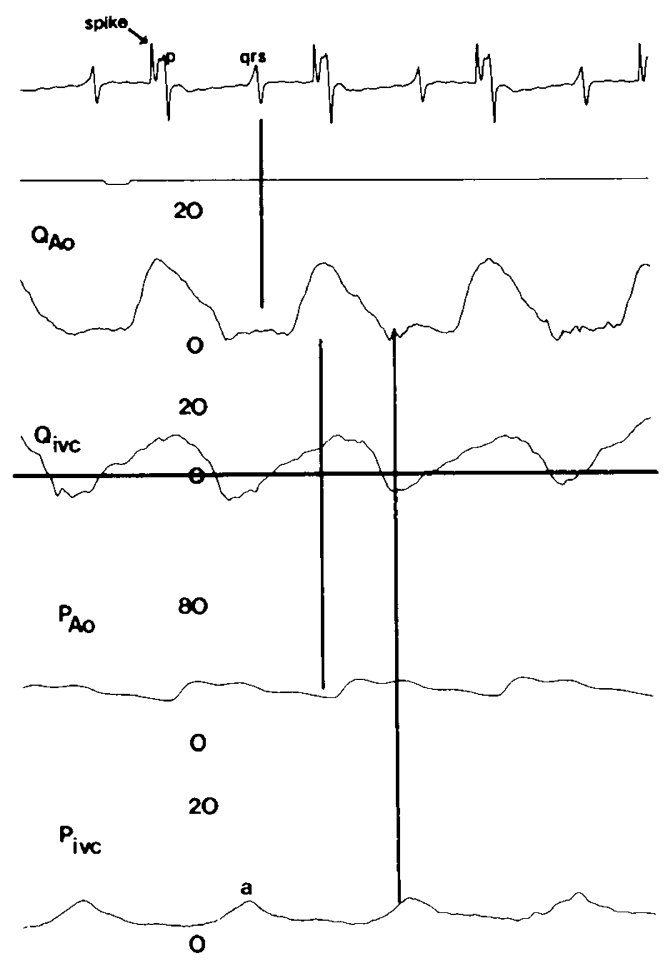

Fig. 3. Blood flows in the IVC toward the heart during the baseline period and produces a positive deflection above the 0 baseline on the chart recording. With atrial pacing, however, blood flow reverses direction during diastole and produces a negative deflection below the 0 baseline. 
for the impairment in diastolic relaxation. If this were the case, then one would have to worry that a prolonged period of atrial tachycardia might result in more severe ventricular dysfunction and even permanent injury to the myocardium.

In summary, in our experiments, we found that reversal of blood flow in the IVC occurred uniformly in fetuses with nonimmune hydrops secondary to rapid atrial pacing. The flow reversal occurred during diastole and appears to reflect atrial contraction against a noncompliant ventricle.

\section{REFERENCES}

1. Silverman NH, Kleinman CS, Rudolph AM, Copel JA, Weinstein EM, Enderlein MA, Golbus M 1985 Fetal atrioventricular valve insufficiency associated with nonimmune hydrops: a two-dimensional echocardiographic and pulsed Doppler ultrasound study. Circulation 72:825-832

2. Nimrod C, Davies D, Harder J, Iwanicki S, Kondo C, Takahashi Y, Maloney
J, Persaud D, Nicholson S 1987 Ultrasound evaluation of tachycardiainduced hydrops in the fetal lamb. Am J Obstet Gynecol 157:655-659

3. Hartley CJ, Cole JS 1974 An ultrasonic pulsed Doppler system for measuring blood flow in small vessels. J Appl Physiol 37:626-629

4. Fisher DJ, Gross DM 1983 The effect of atrial pacing-induced tachycardia on left ventricular contractile function in conscious newborn and adult sheep. Pediatr Res 17:651-656

5. Rudolph AM, Heyman MA 1976 Cardiac output in the fetal lamb: the effects of spontaneous and induced changes of heart rate on right and left ventricular output. Am J Obstet Gynecol 124:183-192

6. Graber JD, Conti CR, Lappe DL, Ross RS 1989 Effect of pacing-induced tachycardia and myocardial ischemia on ventricular pressure-velocity relationships in man. Circulation 46:74-83

7. McLaurin LP, Rolett EL, Grossman W 1973 Impaired left ventricular relaxation during pacing-induced ischemia. Am J Cardiol 32:751-757

8. Laurent D, Bolene-Williams C, Williams FL, Katz LN 1956 Effects of heart rate on coronary flow and cardiac oxygen consumption. Am J Physiol 185:355-364

9. Igarashi K 1984 Cardiac function and myocardial metabolism during tachycardia induced by atrial and ventricular pacing. Pediatr Res 18:369-372 